\title{
TAILORING COLORECTAL CANCER SCREENING BY CONSIDERING RISK OF ADVANCED PROXIMAL NEOPLASIA
}

Thomas F. Imperiale, MD ${ }^{1,2,3}$, Elizabeth A. Glowinski, RN ${ }^{4}$, Ching Lin-Cooper, BS ${ }^{1}$, and David F. Ransohoff, MD ${ }^{5}$

${ }^{1}$ Division of Gastroenterology and Hepatology, Department of Medicine, Indiana University, Indianapolis, IN

${ }^{2}$ Regenstrief Institute, Inc., Indianapolis, IN

${ }^{3}$ Richard L. Roudebush VA Medical Center, Indianapolis, IN

${ }^{4}$ Indianapolis Gastroenterology Research Foundation, Indianapolis, IN

${ }^{5}$ Division of Gastroenterology and Hepatology, Department of Medicine, University of North Carolina at Chapel Hill, Chapel Hill, NC

\section{Abstract}

BACKGROUND—Quantifying risk of advanced proximal colorectal neoplasia might allow tailoring of colorectal cancer screening, with colonoscopy for those at high risk, and less invasive screening for very low-risk persons.

METHODS-We analyzed findings from 10,124 consecutive adults age $\geq 50$ years who underwent screening colonoscopy to the cecum between September 1995 and August 2008. We quantified the risk of advanced neoplasia (tubular adenoma $\geq 1 \mathrm{~cm}$; a polyp with villous histology or high-grade dysplasia; or adenocarcinoma) both proximally (cecum to splenic flexure) and distally (descending colon to anus). Prevalence of advanced proximal neoplasia was quantified by age, gender and distal findings.

RESULTS-Mean (s.d.) age was 57.5 (6.0) years; 44\% were women; 7835 (77\%) had no neoplasia, and 1856 (18\%) had one or more non-advanced adenomas. Overall, 433 subjects (4.3\%) had advanced neoplasia (267 distally; 196 proximally; 30 both), 33 (0.33\%) of which were adenocarcinoma (18 distal, 15 proximal). Risk of advanced proximal neoplasia increased with age decade $(1.13 \%, 2.00 \%$, and $5.26 \%$, respectively; $\mathrm{P}=0.001)$ and was higher in men (relative risk $[R R]=1.91 ; C I, 1.32-2.77$ ). In women younger than 70 years, risk was $1.1 \%$ overall (vs. $2.2 \%$ in men; $\mathrm{RR}=1.98$; CI, $1.42-2.76$ ) and was $0.86 \%$ in those with no distal neoplasia (vs. $1.54 \%$ in men; $\mathrm{RR}=1.81$; CI, 1.20-2.74).

CONCLUSION-Risk of advanced proximal neoplasia is a function of age and gender. Women younger than age 70 have a very low risk, particularly those with no distal adenoma.

() 2012 Elsevier Inc. All rights reserved.

Corresponding author: Thomas F. Imperiale, MD, Regenstrief Institute, Inc. 1050 Wishard Blvd., RG5, Indianapolis, IN 46202, TEL: 317.630.7447, FAX: 317.630.8776, timperia@iupui.edu.

None of the authors has a conflict of interest with any of the material contained in this manuscript. All authors had access to the data, and all had a role in writing, critiquing, and approving the manuscript.

Publisher's Disclaimer: This is a PDF file of an unedited manuscript that has been accepted for publication. As a service to our customers we are providing this early version of the manuscript. The manuscript will undergo copyediting, typesetting, and review of the resulting proof before it is published in its final citable form. Please note that during the production process errors may be discovered which could affect the content, and all legal disclaimers that apply to the journal pertain. 
Sigmoidoscopy with or without occult blood testing may be sufficient and even preferable for screening these subgroups.

\section{Keywords}

Cancer screening; colonoscopy; colorectal cancer; colorectal neoplasm

\section{INTRODUCTION}

Colorectal cancer is the third most common cancer in adults in the U.S. and U.K. and the leading cause of cancer death among non-smokers. ${ }^{1,2}$ Because of its disease burden and natural history, colorectal cancer lends itself well to screening. Several guideline organizations endorse colorectal cancer screening with any of several tests and strategies, and screening rates are increasing among U.S. adults. ${ }^{3-5}$

Although several options are endorsed, ${ }^{3-6}$ colonoscopic screening is the predominant mode of screening in the U.S. ${ }^{7}$ While colonoscopy reduces colorectal cancer incidence ${ }^{8,9}$ and is cost-effective, ${ }^{10-12}$ it requires considerable provider and financial resources. ${ }^{13,14}$ At the same time, use of sigmoidoscopy screening has dramatically decreased in the U.S., ${ }^{15,16}$ despite its being considered an option by major guideline organizations.

Since nearly $80 \%$ of persons who undergo screening colonoscopy will have no neoplasia, ${ }^{8}$ the effectiveness of sigmoidoscopy relative to colonoscopy or to fecal occult blood testing (FOBT) might be clarified if there were a quantitative framework from which to estimate risk for important neoplasia. Better understanding of individual patient risk might allow colorectal cancer screening to be tailored based on risk.

In previous work, we used age, sex, and distal colorectal findings to identify a subgroup at very low-risk for advanced proximal neoplasia. ${ }^{17}$ That subgroup included men and women aged 50-54 years with no distal polyps, women aged 50-54 years with only distal hyperplastic polyps, and women aged 55-59 with no distal polyps. In this paper, we identify a larger, more homogeneous subgroup of persons - women younger than age 70 - with a very low risk for advanced proximal neoplasia, a group for which sigmoidoscopy with or without fecal occult blood testing (FOBT) might be considered an effective and efficient alternative to colonoscopy.

\section{METHODS}

\section{Study design}

This is a retrospective analysis of cross-sectional data from consecutive asymptomatic adults $\geq 50$ years who underwent complete, first-time, screening colonoscopy between September 1995 and August 2008. Results up to June 2001 have been reported previously. ${ }^{17}$ The study was approved by the Institutional Review Board of Indiana University at Indianapolis.

\section{Screening program and eligible population}

The study population is derived from two company-based colorectal cancer prevention programs: Eli Lilly and Company, which began in 1995, and Marathon Oil Company, which began in 2003. Both companies provide screening colonoscopy as a heath benefit to employees, retirees and their dependents. The potentially eligible sample of employees and retirees from which the study cohort has been previously described as $32 \%$ female, $90 \%$ Caucasian, middle to upper-middle class in socioeconomic status.(17) The procedures for patient enrollment have been described previously. ${ }^{17,18}$ 


\section{Study procedures and definitions}

The location and size of all polyps and other lesions were determined prior to removal. Methods for assessing location and size were chosen by the endoscopist. Distal location included the descending colon, sigmoid colon, and rectum. All other locations were considered "proximal." Colonic segments with more than one polyp were categorized according to the most advanced polyp. Distal findings were simulated from colonoscopy reports rather than based on actual sigmoidoscopy.

Pathologic specimens were examined by one of three board-certified pathologists, who classified polyps according to World Health Organization criteria. ${ }^{19}$ Histological characteristics of polyps were reported as normal mucosa, hyperplastic, serrated, tubular, tubulovillous or villous. An advanced neoplasm was defined as a tubular or serrated adenoma $\geq 1 \mathrm{~cm}$ or any polyp with villous histology, high-grade dysplasia, or adenocarcinoma. Lipomas, lymphoid aggregates, and non-specific findings were considered normal findings.

\section{Statistical analysis}

Descriptive statistics were used for basic demographic features and the prevalence of each category of findings. Using simple proportions and exact $95 \%$ confidence intervals, we calculated the prevalence (or absolute risk) of advanced neoplasia anywhere, distally, and proximally. We also calculated the prevalence of advanced proximal neoplasia according to the most advanced distal finding, and according to gender and age decade (ages 50-59, 6069 , and 70 and older). For each age group, gender, and for certain subgroups of distal findings, we report the number of persons needed to be screened to detect one advanced proximal neoplasm (most of which are advanced adenomas) and one proximal adenocarcinoma. ${ }^{20}$ Data were managed with Microsoft Excel, version 11 (Microsoft). All analyses were performed using SPSS software, version 16.0. Exact methods were used to calculate $95 \%$ confidence limits for all proportions. A P-value less than 0.05 was considered statistically significant.

\section{Role of the funding source}

The funding source had no role in the design, data collection, analysis or decision to submit the paper for publication.

\section{RESULTS}

Between September 1995 and August 2008, 10,124 persons aged $\geq 50$ years underwent complete colonoscopic screening to the cecum. The cohort had a mean (+/- SD) age of 57.5 (6.0) years and was comprised of $44 \%$ women ( $\mathrm{N}=4454$; mean age 57.4 (6.1) years). The mean age of the 5,670 men was 57.5 (6.0) years.

Table 1 shows the most advanced finding anywhere in the colon and rectum. Just over 77\% of patients had no neoplasia; this included $13.5 \%$ with hyperplastic polyps. Eighteen percent had non-advanced neoplasia, while $4.3 \%$ had advanced neoplasia, $62 \%$ of which was located distal to the splenic flexure. A total of 33 cancers $(0.33 \%)$ were detected: $19(0.34 \%)$ among 5,670 men and $14(0.31 \%)$ among 4,454 women. Eighteen patients (10 men, 8 women) had a distal cancer. Of the 15 patients with proximal cancers, three (20\%) had associated distal neoplasia ( 2 advanced, 1 non-advanced), 4 had distal hyperplastic polyps, and 8 had no distal polyp of any kind. (Table 2)

The prevalence of advanced neoplasia by location, age decade, and gender is shown in Table 2. Risk of any advanced neoplasia increased with age decade for both men and women 
$(\mathrm{P}<0.001)$ and was higher in men for each decade. However, when considered by location, the risk of advanced neoplasia - both proximal and distal - increased by age decade for men only. Among women, the risk of advanced distal neoplasia was no different by age decade, while the risk of advanced proximal neoplasia was higher in women aged $\geq 70$ years compared with women $<70$ years $(\mathrm{P}=0.001)$.

Table 3 shows the prevalence of advanced proximal neoplasia based on the most advanced distal finding. Among persons with distal hyperplastic polyps, the risk of advanced proximal neoplasia was $1.61 \%$ (95\% CI, 0.98-2.47\%), which was not statistically different from persons with no distal polyps, in whom the risk was $1.50 \%$ (95\% CI, 1.24-1.80\%), for a relative risk (RR) of 1.07 (CI, 0.67-1.71). The lack of a difference in risk for advanced proximal neoplasia was present for both men (1.99\% for no distal polyps versus $1.93 \%$ for distal hyperplastic polyps) and women (0.95\% versus $1.07 \%)$. Among those with distal hyperplastic polyps, the risk for advanced proximal neoplasia was not statistically different between men and women (1.93\% versus $1.07 \%$; RR=1.80; CI, 0.69-4.76). However, among those with no distal polyps, the risk for advanced proximal neoplasia was greater in men $(\mathrm{RR}=2.10$; CI, 1.41-3.12).

The presence of distal neoplasia increased the risk for advanced proximal neolasia, and was $3.14 \%$ for persons with one or more non-advanced distal adenomas and $11.2 \%$ for those with advanced distal neoplasia, with respective RRs of 2.09 (CI, 1.42-3.07) and 7.49 (CI, 5.09-10.90) compared to persons with no distal neoplasia (Table 3). For both categories of distal findings, there was no difference in the risk for advanced proximal neoplasia between men and women. Risk of advanced proximal neoplasia in those with one or more nonadvanced distal tubular adenoma was $3.1 \%$ overall, and did not differ statistically between men and women $(3.4 \%$ vs. $2.7 \%$; $\mathrm{P}=0.5)$ or between $50-59$ and $60-69$ year olds $(2.2 \%$ vs. $3.5 \% ; \mathrm{P}=0.3)$, but was higher in persons age 70 and older $(13.5 \%)$.

Absolute risks of advanced proximal neoplasia by age group and sex, both overall and among those with no distal neoplasia, are shown in Table 4 . The risk of advanced proximal neoplasia increased across the three age categories ( $\mathrm{P}<0.009$ for all groups). Among men and women with no distal neoplasia, men had nearly twice the risk of advanced proximal neoplasia ( $R R=1.91$; CI, 1.32-2.77). Women in the 50-59 and 60-69 year old age groups had a very low risk for advanced proximal neoplasia, particularly those with no distal neoplasia, in which the risks were $0.85 \%$ and $0.88 \%$, respectively (Table 4 ), and $0.86 \%$ overall. For men under age 70 with no distal neoplasia, the risk was $1.54 \%(\mathrm{RR}=1.81$ for men vs. women; CI, 1.20-2.74). Based on the risks of advanced proximal neoplasia for these four subgroups, Table 5 shows the numbers of persons who would need to be screened with colonoscopy to detect one person with it. For persons age $\geq 70$ years and for men ages 60 69 years old, the yield of colonoscopy was high, with numbers needed to screen ranging from 11 to 35 . For women under age 70 and for men with no distal neoplasia, the yield of colonoscopy was lower, with numbers needed to screen between 89 and 93 . Women under age 70 with no distal neoplasia had the lowest yield, with numbers needed to screen of 114 to 118 .

The number of patients needed to screen with colonoscopy to detect one proximal cancer were much higher than for an advanced proximal neoplasm. Among women younger than 70 years, the number needed to screen to detect one proximal cancer was 2,120 (CI, 588 to 10,000) overall and 1,926 (CI, 526-10,000) among those with no distal neoplasia. In particular, among women 50 to 59 years old, the number needed to screen was 3,221 (CI, $588-\infty)$ overall, and was 2,500 (CI, $455-\infty)$ among those with no distal polyps, suggesting a very low yield of colonoscopy for proximal cancer in the absence of a distal adenoma. For women 60-69 years old, the number needed to screen to detect one proximal 
cancer was 1019 (CI, $182-\infty)$. Among men < 70 years with no distal neoplasia, the number needed to screen to detect one proximal cancer was 921 (CI, 400-2500), and was 853 (CI, 333-3333) overall in men < age 60.

\section{DISCUSSION}

Our findings support and extend previous findings regarding the relationships between advanced proximal neoplasia and age, gender, and distal colorectal findings. ${ }^{17,18,21-25}$ Consistent with previous studies, this study shows that distal adenomas, but not distal hyperplastic polyps, are associated with increased risk for advanced proximal neoplasia. 21,23,24,26,27 Further, we have identified at least one large, clinically-important subgroup with very low risk for this finding: women younger than 70 years old who have no distal adenomas. The yield of colonoscopy for advanced neoplasia beyond what sigmoidoscopy would reveal is very low for women younger than age 70; it is extremely low when the outcome is a proximal cancer. Considered together, the findings provide a basis for tailoring the use of screening colonoscopy and, specifically, for considering not using it solely or routinely as a primary screening test for women under age 60 and perhaps for women under age 70 . While we found nearly identical risk estimates for advanced proximal neoplasia between women 50-59 years of age and those 60-69 years of age, the number of women in the 60-69 age group was small relative to the 50-59 age group, and our findings among the older age group require further study and larger numbers to validate the findings. Further, cost-effectiveness analysis would be useful to explicitly quantify benefits and harms among tailored screening strategies for these groups, and is beyond the scope of this report. Adding a sensitive FOBT ${ }^{282930}$ to sigmoidoscopy would mitigate some of the difference in detection of advanced proximal neoplasia between sigmoidoscopy and colonoscopy, as suggested in some quantitative analyses. ${ }^{11,31,32}$

The concept of tailoring screening intensity based on risk is not new. Colorectal cancer screening is tailored to be more intensive for high-risk subgroups (e.g., familial adenomatous polyposis, hereditary non-polyposis CRC syndromes), and for persons with a first-degree relative with colorectal cancer. ${ }^{4,5}$ In a parallel fashion, improved knowledge about subgroups with a particularly low risk for colorectal cancer might allow more effective tailoring of screening: those at very low-risk could be screened less invasively or perhaps later than age 50. Such a scenario has appeal in an era of cost containment; moreover, after a quantitative consideration of marginal risk vs. marginal benefit, it may simply make sense to many physicians and patients.

The risk difference in the low-risk group is parallel to the magnitude currently used to make screening decisions when there is a family history of colorectal cancer. Based on relative risks that are elevated 2-to-3-fold in persons with a positive family history, 4,5 we begin screening sooner or recommend more invasive testing. In this study, women < age 70 had both a very low absolute risk of advanced neoplasia (with higher numbers needed to screen) and a relative risk that was roughly half that of similarly-aged men. Instead of tailoring for increased risk (as with family history), we might consider tailoring for persons at lower risk, and screen them either less invasively, later, or both.

Several features could be considered candidate risk factors for tailoring colorectal cancer screening. Among demographic features, gender is particularly worthy of consideration. Epidemiological and clinical data indicate that the age-adjusted risk for colorectal cancer in men is nearly twice that for women. ${ }^{33-35}$ Several studies have found that male gender is an independent risk factor for both colorectal cancer and for adenomatous polyps. ${ }^{18,21,25,36} \mathrm{~A}$ systematic review of 17 screening studies and more than 924,000 persons found that men 
have a pooled relative risk for advanced neoplasia of 1.83 (CI, 1.69-1.97) that is present in all age groups. ${ }^{36}$

Our findings in women differ from those of others, ${ }^{37}$ which found a higher prevalence of advanced neoplasia ( $4.6 \%$ versus $2.6 \%$ in the current study) and a higher proportion of proximal lesions in 1,463 women from 4 military medical centers. The prevalence of advanced neoplasia was numerically higher in this other study for each age group, suggesting that factors other than age (such as family history of colorectal cancer, cigarette smoking, and body mass index) might account for the differences in risk. The reason for the difference in distribution of advanced adenomas is uncertain. Additional data in women based on these risk factors would be useful to understand how each factor affects the prevalence of advanced neoplasia.

Another candidate feature for tailoring is distal colorectal findings. An extensive literature supports a higher risk of advanced neoplasia in the proximal colon when distal neoplasia is present, with the magnitude of risk directly related to the degree or severity of distal neoplasia. ${ }^{18,21,23-26,38}$ Findings from this study provide further support for this literature and for using distal findings along with other factors to estimate the risk for APN.

Use of sigmoidoscopy in the U.S. has declined for several reasons, including a lack of training and inadequate reimbursement ${ }^{7,39}$ + Lewis 1999; however, a case can be made to increase its use and to address the issues of training and reimbursement. First, quantitative analyses suggest that it is an acceptable option by itself. ${ }^{11,31}$ Second, analyses done by the U. S. Preventive Services Task Force and Institute of Medicine show that when sigmoidoscopy is combined with guaiac-based FOBT in a program of screening, it may be as effective or more effective than screening colonoscopy because it detects fast-growing lesions that occur between colonoscopies. ${ }^{11,12,40,41}$ The combination of sigmoidoscopy every 5 years with newer high sensitivity FOBT $28,29,42,43$ annually may provide even more benefit in a screening program ${ }^{44}$ by detecting fast growing lesions and those missed by colonoscopy. Third, a screening strategy of once-only sigmoidoscopy recently has been shown to reduce incidence and mortality from left-sided colorectal cancer for at least 10 years, ${ }^{45,46}$ suggesting that such an approach is worth considering. Last, if colonoscopy has substantially decreased effectiveness in the right colon as several but not all studies suggest, ${ }^{47,4849,50}$ then the marginal gain from colonoscopy compared to sigmoidoscopy may be negligible. The question of marginal effectiveness of colonoscopy over sigmoidoscopy was addressed in a population-based study in which the relative effectiveness of sigmoidoscopy compared with colonoscopy was $76 \%$ if sigmoidoscopy reached the junction of the descending colon and sigmoid colon, and 83\% if sigmoidoscopy reached the splenic flexure. ${ }^{51}$ Our data help identify a subgroup with very low risk of APN neoplasia; these data may be useful in selecting optimal screening strategies that balance benefits and harms.

This study has limitations that require comment. Distal findings were not based on an initial examination with sigmoidoscopy, but rather, were simulated from colonoscopy. This analysis assumes that a sigmoidoscope would reach the proximal descending colon, an assumption that may be overly optimistic, particularly among non-specialists who do not perform the procedure on a regular basis. We were unable to examine the effect of other variables that might further help stratify risk for advanced neoplasia (such as body mass index and cigarette smoking) because these factors were not routinely collected. Perhaps the most important limitation is the uncertain clinical importance of the advanced adenoma, which comprises most of advanced neoplasia. As we have discussed before, ${ }^{17,18}$ the natural history of "advanced adenoma" is not clear. In deciding about intervention, behavior, not appearance, is what counts. ${ }^{52,53}$ The lack of data on both growth rates of advanced adenomas and factors affecting growth preclude knowing how to optimize strategies for 
colorectal cancer screening and surveillance. Finally, while the results may not generalize well beyond Caucasian persons who are willing to undergo screening colonoscopy, a recent study of screening colonoscopy showed similar rates of neoplasia among Caucasians, Hispanics, and African-Americans.(Levitsky 2011)

In conclusion, the findings from more than 10,000 index screening colonoscopies show that the risk of APN differs based on age and gender, suggesting that use of screening colonoscopy could be tailored based on risk. In women under age 70, the risk for APN was very low, especially in those with no distal adenoma, while the risk of a proximal cancer was extremely low. These findings may be useful for tailoring CRC screening. In women under age 60 or 70, consideration should be given to whether sigmoidoscopy with or without a sensitive FOBT is sufficient screening. Further consideration of tailoring requires independent validation of our findings and an explicit quantitative assessment of its incremental benefits, risks, and cost.

\section{Acknowledgments}

FUNDING: National Institutes of Health, National Cancer Institute, grant \# R01 CA 104459 (Drs. Imperiale, Ransohoff; Ms. Glowinski)

\section{References}

1. Jemal A, Siegal RWE, Hao Y, Xu J, Thun MJ. Cancer statistics, 2009. CA Cancer J Clin. 2009; 59(4):225-249. [PubMed: 19474385]

2. Jemal A, Thun MJ, Ries LA, et al. Annual report to the nation on the status of cancer, 1975-2005, featuring trends in lung cancer, tobacco use, and tobacco control. J Natl Cancer Inst. Dec 3; 2008 100(23):1672-1694. [PubMed: 19033571]

3. Screening for colorectal cancer: U S. Preventive Services Task Force recommendation statement. Ann Intern Med. Nov 4; 2008 149(9):627-637. [PubMed: 18838716]

4. Levin B, Lieberman DA, McFarland B, et al. Screening and surveillance for the early detection of colorectal cancer and adenomatous polyps, 2008: a joint guideline from the American Cancer Society, the US Multi-Society Task Force on Colorectal Cancer, and the American College of Radiology. Gastroenterology. May; 2008 134(5):1570-1595. [PubMed: 18384785]

5. Rex DK, Johnson DA, Anderson JC, Schoenfeld PS, Burke CA, Inadomi JM. American College of Gastroenterology guidelines for colorectal cancer screening 2009 [corrected]. Am J Gastroenterol. Mar; 2009 104(3):739-750. [PubMed: 19240699]

6. von Karsa L, Anttila A, Ronco A, et al. Cancer screening in the European Union. Report on the implementation of the Council Recommendation on cancer screenin g- First Report. 2008

7. Klabunde CN, Lanier D, Nadel MR, McLeod C, Yuan G, Vernon SW. Colorectal cancer screening by primary care physicians: recommendations and practices, 2006-2007. Am J Prev Med. Jul; 2009 37(1):8-16. [PubMed: 19442479]

8. Kahi CJ, Rex DK, Imperiale TF. Screening, surveillance, and primary prevention for colorectal cancer: a review of the recent literature. Gastroenterology. Aug; 2008 135(2):380-399. [PubMed: 18582467]

9. Winawer SJ, Zauber AG, Ho MN, et al. Prevention of colorectal cancer by colonoscopic polypectomy. The National Polyp Study Workgroup. N Engl J Med. Dec 30; 1993 329(27):19771981. [PubMed: 8247072]

10. Levin B, Lieberman DA, McFarland B, et al. Screening and surveillance for the early detection of colorectal cancer and adenomatous polyps, 2008: A joint guideline from the American Cancer Society, the US Multi-Society Task Force on Colorectal Cancer, and the American College of Radiology. CA Cancer J Clin. 2008; 58:130-160. [PubMed: 18322143]

11. Pignone, MP.; Russell, L.; Wagner, JL., editors. Economic Models of Colorectal Cancer Screening in Average-Risk Adults: Workshop Summary. Washington, D.C: Institute of Medicine and National Research Council; 2005. 
12. Pignone MP, Saha S, Hoerger T, Mandelblatt J. Cost-effectiveness analysis of colorectal cancer screening: a systematic review for the U.S. Preventive Services Task Force. Ann Intern Med. 2002; 137(2):96-104. [PubMed: 12118964]

13. Seeff LC, Manninen DL, Dong FB, et al. Is there endoscopic capacity to provide colorectal cancer screening to the unscreened population in the United States? Gastroenterology. Dec; 2004 127(6): 1661-1669. [PubMed: 15578502]

14. Seeff LC, Richards TB, Shapiro JA, et al. How many endoscopies are performed for colorectal cancer screening? Results from CDC's survey of endoscopic capacity. Gastroenterology. Dec; 2004 127(6):1670-1677. [PubMed: 15578503]

15. Schenck AP, Peacock SC, Klabunde CN, Lapin P, Coan JF, Brown MB. Trends in colorectal cancer test use $i$ the medicare population, 1998-2005. Am J Prev Med. 2009; 37(1):1-7. [PubMed: 19423273]

16. Chen X, White MC, Peipins LA, Seeff LA. Increase in screening for colorectal cancer in older Americans: results from a national survey. J Am Geriatr Soc. 2008; 56:1511-1516. [PubMed: 18662217]

17. Imperiale TF, Wagner DR, Lin CY, Larkin GN, Rogge JD, Ransohoff DF. Using risk for advanced proximal colonic neoplasia to tailor endoscopic screening for colorectal cancer. Ann Intern Med. 2003; 139:949-965.

18. Imperiale TF, Wagner DR, Lin CY, Larkin GN, Rogge JD, Ransohoff DF. Risk of advanced proximal neoplasms in asymptomatic adults according to the distal colorectal findings. N Engl J Med. 2000; 343(3):169-174. [PubMed: 10900275]

19. Konishi F, Morson BC. Pathology of colorectal adenomas: a colonoscopic survey. J Clin Pathol. 1982; 35:830-841. [PubMed: 7107955]

20. Laupacis A, Sackett D, Roberts R. An assessment of clinically useful measures of the consequences of treatment. N Engl J Med. 1988; 318:1728-1733. [PubMed: 3374545]

21. Levin TR, Palitz A, Grossman S, et al. Predicting advanced proximal colonic neoplasia with screening sigmoidoscopy. JAMA. 1999; 281(17):1611-1617. [PubMed: 10235154]

22. Lieberman DA, Prindiville S, Weiss DG, Willett W. Risk factors for advanced colonic neoplasia and hyperplastic polyps in asymptomatic individuals. JAMA. Dec 10; 2003 290(22):2959-2967. [PubMed: 14665657]

23. Schoen RE, Corle D, Cranston L, et al. Is colonoscopy needed for the nonadvanced adenoma found on sigmoidoscopy? The Polyp Prevention Trial. Gastroenterology. 1998; 115(3):533-541. [PubMed: 9721149]

24. Wallace MB, Kemp JA, Trnka YM, Donovan JM, Farraye FA. Is colonoscopy indicated for small adenomas found by screening flexible sigmoidoscopy? Annals of Internal Medicine. 1998; 129(4): 273-278. [PubMed: 9729179]

25. Rex DK, Lehman GA, TMU, et al. Colonic neoplasia in asymptomatic persons with negative fecal occult blood tests: influence of age, gender, and family history. Am J Gastroenterol. 1993; 88(6): 825-831. [PubMed: 8503374]

26. Lieberman DA, Weiss DG, Bond JH, Ahnen DJ, Garewal H, Chejfec G. Use of colonoscopy to screen asymptomatic adults for colorectal cancer. Veterans Affairs Cooperative Study Group 380. N Engl J Med. 2000; 343(3):162-168. [PubMed: 10900274]

27. Lin OS, Schembre DB, McCormick SE, et al. Risk of proximal colorectal neoplasia among asymptomatic patients with distal hyperplastic polyps. Am J Med. 2005; 118(10):1113-1119. [PubMed: 16194642]

28. Levi Z, Rozen P, Hazazi R, et al. A quantitative immunochemical fecal occult blood test for colorectal neoplasia. Ann Intern Med. Feb 20; 2007 146(4):244-255. [PubMed: 17310048]

29. Morikawa T, Kato J, Yamaji Y, Wada R, Mitsushima T, Shiratori Y. A comparison of the immunochemical fecal occult blood test and total colonoscopy in the asymptomatic population. Gastroenterology. Aug; 2005 129(2):422-428. [PubMed: 16083699]

30. Whitlock EP, Lin JS, Liles E, Beil TL, Fu R. Screening for colorectal cancer: a targeted, updated systematic review for the U.S. Preventive Services Task Force. Ann Intern Med. Nov 4; 2008 149(9):638-658. [PubMed: 18838718] 
31. Pignone M, Rich M, Teutsch SM, Berg AO, Lohr KN. Screening for colorectal cancer in adults at average risk: a summary of the evidence for the U.S. Preventive Services Task Force. Ann Int Med. 2002; 137:132-141. [PubMed: 12118972]

32. Zauber AG, Lansdorp-Vogelaar I, Knudsen AB, Wilschut J, van Ballegooijen M, Kuntz KM. Evaluating test strategies for colorectal cancer screening: a decision analysis for the U.S. Preventive Services Task Force. Ann Intern Med. Nov 4; 2008 149(9):659-669. [PubMed: 18838717]

33. Smith RA, Cokkinides V, Brawley OW. Cancer screening in the United States, 2009: a review of current American Cancer Society guidelines and issues in cancer screening. CA Cancer J Clin. Jan-Feb;2009 59(1):27-41. [PubMed: 19147867]

34. Ferlitsch M, Reinhart K, Pramhas S, et al. Sex-specific prevalence of acenomas, advanced adenomas, and colorectal cancer in individuals undergoing screening colonoscopy. JAMA. 2011; 306(12):1352-1358. [PubMed: 21954479]

35. Regula J, Rupinski M, Kraszewska E, et al. Colonoscopy in colorectal-cancer screening for detection of advanced neoplasia. N Engl J Med. 2006; 355:1863-1872. [PubMed: 17079760]

36. Nyugen S. Gender as a risk factor for advanced neoplasia and colorectal cancer: a systematic review and meta-analysis. Clin Gastroenterol Hepatol. 2009; 7:676-681. [PubMed: 19514116]

37. Schoenfeld P, Cash B, Flood A, et al. Colonoscopic screening of average-risk women for colorectal neoplasia. N Engl J Med. May 19; 2005 352(20):2061-2068. [PubMed: 15901859]

38. Schoen RE, Weissfeld JL, Pinsky PF, Riley T. Yield of advanced adenoma and cancer based on polyp size detected at screening flexible sigmoidoscopy. Gastroenterology. Dec; 2006 131(6): 1683-1689. [PubMed: 17188959]

39. Increased use of colorectal cancer tests - United States, 2002 and 2004. MMWR Morb Mortal Wkly Rep. 2006; 55(11):308-311. [PubMed: 16557215]

40. Ransohoff DF. Have we oversold colonoscopy? Gastroenterology. Dec.2005 129(6):1815. [PubMed: 16344048]

41. Ransohoff DF. Colon cancer screening in 2005: status and challenges. Gastroenterology. May; 2005 128(6):1685-1695. [PubMed: 15887159]

42. Allison JE. Colorectal cancer screening guidelines: the importance of evidence and transparency. Gastroenterology. 2010; 138(5):1648-1652. [PubMed: 20211181]

43. Allison JE, Sakoda LC, Levin TR, et al. Screening for colorectal neoplasms with new fecal occult blood tests: update on performance characteristics. J Natl Cancer Inst. 2008; 99(19):1462-1470. [PubMed: 17895475]

44. Ransohoff DF. Can endoscopy protect against colorectal cancer? An RCT. Lancet. Apr 27.

45. Atkin WS, Edwards R, Kralj-Hans I, et al. Once-only flexible sigmoidoscopy screening in prevention of colorectal cancer: multicentre randomised controlled trial. Lancet. 2010

46. Segnan N, Armaroli P, Bonelli L, et al. Once-only sigmoidoscopy in colorectal cancer screening: follow-up findings of the Italian Randomized Controlled Trial--SCORE. J Natl Cancer Inst. Sep 7; 2011 103(17):1310-1322. [PubMed: 21852264]

47. Baxter NN, Goldwasser MA, Paszat LF, Saskin R, Urbach DR, Rabeneck L. Association of colonoscopy and death from colorectal cancer. Ann Intern Med. Jan 6; 2009 150(1):1-8. [PubMed: 19075198]

48. Brenner H, Hoffmeister M, Arndt V, Stegmaier C, Altenhofen L, Haug U. Protection from rightand left-sided colorectal neoplasms after colonoscopy: population-based study. J Natl Cancer Inst. Jan 20; 2010 102(2):89-95. [PubMed: 20042716]

49. Singh H, Nugent Z, Demers AA, Kliewer EV, Mahmud SM, Bernstein CN. The reduction in colorectal cancer mortality after colonoscopy varies by site of the cancer. Gastroenterology. Oct; 139(4):1128-1137. [PubMed: 20600026]

50. Brenner H, Chang-Claude J, Seiler CM, Rickert A, Hoffmeister M. Protection from colorectal cancer after colonoscopy: a population-based, case-control study. Annals of Internal Medicine. 2011; 154(1):22-30. [PubMed: 21200035]

51. Brenner H, Chang-Claude J, Seiler CM, Sturmer T, Hoffmeister M. Potential for colorectal cancer prevention of sigmoidoscopy versus colonoscopy: population-based case-control study. Cancer Epidemiol Biomarkers Prev. 2007; 16(3):494-499. [PubMed: 17337649] 
52. Barry MJ. Screening for prostate cancer--the controversy that refuses to die. N Engl J Med. Mar 26; 2009 360(13):1351-1354. [PubMed: 19297564]

53. Folkman J, Kalluri R. Cancer without disease. Nature. Feb 26.2004 427(6977):787. [PubMed: 14985739] 
Table 1

Most advanced finding present on screening colonoscopy

\begin{tabular}{lcc}
\hline Finding & N & Percent \\
No neoplasia & 7,835 & $77 \%$ \\
$\quad$ Hyperplastic polyps & 1,367 & $13.5 \%$ \\
$\geq 1$ tubular adenoma $<1 \mathrm{~cm}$ & 1,856 & $18 \%$ \\
Advanced neoplasia * & 433 & $4.3 \%$ \\
Adenocarcinoma & 33 & $0.33 \%$ \\
\hline
\end{tabular}

$62 \%$ of advanced neoplasia was distal to the splenic fixture 




Page 12 
Table 3

Risk of advanced proximal neoplasia (APN) based on distal findings

\begin{tabular}{lcccc}
\hline Distal Finding & Total N & APN N & Risk of APN \% (95\% CI) & Relative Risk (95\% CI) \\
No polyp & 7594 & 114 & $1.50(1.24-1.80)$ & 1.0 \\
Hyperplastic polyp & 1244 & 20 & $1.61(0.98-2.47)$ & $1.07(0.67-1.71)$ \\
Tubular adenoma(s) $<1 \mathrm{~cm}$ & 1019 & 32 & $3.14(2.16-4.40)$ & $2.09(1.42-3.07)$ \\
Advanced neoplasia & 267 & 30 & $11.2(7.71-15.7)$ & $7.49(5.09-10.90)$ \\
\hline
\end{tabular}




\section{Table 4}

Absolute risk of advanced proximal neoplasia by age, sex, and distal findings

\begin{tabular}{lccc}
\hline & \multicolumn{2}{c}{ Number with advanced proximal neoplasia/total N (\%) } \\
Group & Age 50-59 & Age 60-69 & Age $\geq 70$ \\
All men & $1.75 \%(70 / 3999)$ & $3.42 \%(49 / 1433)$ & $8.82 \%(21 / 238)$ \\
Men, no distal neoplasia & $1.38 \%(47 / 3413)$ & $2.85 \%(34 / 1194)$ & $7.61 \%(14 / 184)$ \\
All women & $1.11 \%(36 / 3221)$ & $1.08 \%(11 / 1019)$ & $4.21 \%(9 / 214)$ \\
Women, no distal neoplasia & $0.85 \%(25 / 2942)$ & $0.88 \%(8 / 909)$ & $3.06 \%(6 / 196)$ \\
\hline
\end{tabular}


Table 5

Number needed to screen to detect 1 person with advanced proximal neoplasia

\begin{tabular}{lccc}
\hline Group & Ages 50-59 & Ages 60-69 & Ages $\geq 70$ \\
All men & $57(45-73)$ & $29(22-39)$ & $11(8-18)$ \\
Men, no distal neoplasia & $73(55-99)$ & $35(25-51)$ & $13(8-24)$ \\
All women & $89(65-128)$ & $93(52-185)$ & $24(13-52)$ \\
Women, no distal neoplasia & $118(80-182)$ & $114(58-263)$ & $33(5-88)$ \\
\hline
\end{tabular}

